\title{
Insights on Epidemiology, Pathogenesis, Diagnosis and Possible Treatment of COVID-19 Infection
}

\author{
Shashank Kumar Maurya ${ }^{1}$ (i) $\cdot$ Amit Bhattacharya $^{1} \cdot$ Pooja Shukla $^{2} \cdot$ \\ Rajnikant Mishra ${ }^{3}$
}

Received: 17 April 2020/Revised: 3 May 2021/Accepted: 10 November 2021/Published online: 15 January 2022

(C) The National Academy of Sciences, India 2022

\begin{abstract}
The sudden outbreak of the novel coronavirus infection (COVID-19, SARS-CoV-2 virus) is posing a significant threat by affecting millions of people across the globe showing mild to severe symptoms of pneumonia and acute respiratory distress. The absence of precise information on primary transmission, diagnosis, prognosis, and therapeutics for patients with COVID-19 makes prevention and control tough. In the current scenario, only supportive treatment is available, which in turn possess a biggest challenge for scientists to develop specific drugs and vaccines for COVID-19. Further, India, with the second largest populated country and fluctuating climatic conditions quarterly, has high vulnerability towards COVID-19
\end{abstract}

The review article will provide a basic understanding on the biology of COVID-19 and the effect of its infection on humans. It will also provide insight on the use of anti-viral and anti-malaria drugs as possible alternative treatment strategies.

Shashank Kumar Maurya

maurya.shashankkumar@gmail.com

Amit Bhattacharya

amit4dec@yahoo.com

Pooja Shukla

shuklapooja909@gmail.com

Rajnikant Mishra

rmishraa@bhu.ac.in

1 Department of Zoology, Ramjas College, University of Delhi, Delhi 110007, India

2 Department of Genetics and Molecular Biology, National Institute of Malaria Research, Indian Council of Medical Research, Delhi 110077, India

3 Biochemistry and Molecular Biology Laboratory, Department of Zoology, Banaras Hindu University, Varanasi 221005, India infection. Thus, this highlights the importance of a better understanding of the COVID-19 infection, pathology, diagnosis and its treatment. The present review article has been intended to discuss the COVID-19 biology, mechanism of infection in humans with primary effects on pregnancy, the nervous system, diabetes, and cardiovascular disease. The article will also discuss the drug repurposing strategy as an alternative line of treatment and clinical practices recommended by the World Health Organization and other government agencies and represent the COVID-19 scenario with the Indian context.

Keywords COVID-19 · Coronavirus ·

Acute respiratory illness $\cdot$ Repurposed drugs

\section{Introduction}

Recently in December 2019, patients were presented with symptoms of fever or dry cough having either usual or reduced count of white blood cells from Wuhan city of China. They were classified as bearing 'Fever of Unknown Origin' along with pneumonia [1]. Later on, Severe Acute Respiratory Syndrome Coronavirus 2 (SARS-CoV-2) was identified as a causative agent, potentially having humanto-human transmission [1]. The World Health Organization (WHO) declared 'Public Health Emergency of International Concern' at the outbreak of infection induced by COVID-19 on 30th January 2020. On 12th January 2020, WHO termed the virus as '2019 novel coronavirus' (2019nCoV), and subsequently on 11th February 2020, the disease was designated as 'coronavirus disease' (COVID-19). The genome analyses of SARS-CoV-2 have shown the evolution of these viruses into L- and S-types [2]. The prevalence of S-type $(\sim 30 \%)$ is reported to be less than 
that of L-type $(\sim 70 \%)$. Further, the S-type is evolutionarily older and less aggressive, while the L-type, being more contagious, showed higher frequency during the early stages of the COVID outbreak in Wuhan. Nonetheless, its frequency declined gradually. However, this decline was soon followed up by a second wave which has affected several countries, however, India battles a devastating COVID surge since April 2021.

\section{Coronavirus (CoVs)}

Coronaviruses are a group of varied and large-enveloped viruses enclosing non-segmented and positive-sense singlestranded RNA. They have been observed to cause enteric and respiratory diseases. Besides, they also affect the liver and neurological system with varying severity among animals and humans [3]. Human corona virus subtypes like HCoV-HKU1, HCoV-229E, HCoV-NL63, and HCoVOC43 lead to mild respiratory sickness [4]. However, the worldwide spread of two novel corona viruses, namely SARS-CoV and the Middle East Respiratory Syndrome $\mathrm{CoV}$ (MERS-CoV) in the last 20 years has attracted global attention due to their high lethal potential. More than 8,000 people with around a $10 \%$ mortality rate worldwide have died due to widespread SARS-CoV infection. However, the MERS-CoV was infested in around 857 patients with a high death rate (35\%) [5]. A recent outbreak of SARSCoV-2 in China has rapidly spread throughout the world. Genome analysis revealed that, like SARS-CoV and MERS-CoV, the SARS-CoV-2 also falls in the same betacorona virus $(\beta \mathrm{CoV})$ clade and shows high homology with SARS-CoV [6]. Consequently, SARS-CoV-2 shares analogous pneumonia pathogenesis as instigated by SARS$\mathrm{CoV}$ or MERS-CoV-infected cases, and its entrance into the human host cells has been recognized utilizing a similar receptor as SARS-CoV. Since most CoVs have almost the same viral structure and infection pathway, observations related to mechanisms of infections may also be applicable for SARS-CoV-2 [7].

\section{The SARS-Cov-2}

SARS-CoV-2 belongs to Sarbecovirus subgenus of the genus Beta-coronavirus [6]. It possesses $29.9 \mathrm{~kb}$ long RNA consisting of 5' untranslated region (5' UTR), replicase gene, S gene (for Spike protein), E gene (for envelope protein), $\mathrm{M}$ gene (for Membrane protein), $\mathrm{N}$ gene (for Nucleocapsid protein) and 3' poly (A) UTR with unknown open reading frames [8]. It is surrounded by an envelope and spikes with spherical, oval, or pleomorphic shapes of 60-140 nm diameters. Although SARS-CoV-2 has distinct gene sequences from other corona viruses, it exhibits high sequence identity $(80.26 \%)$ to the human SARS-CoV genome [7]. As per WHO, it appears as a chimera of coronavirus of a bat and of an unknown origin. Nevertheless, snakes are considered a possible source for SARSCoV-2 after comparing with other animals. Another research group reported that Chinese chrysanthemumheaded bats are closely related to SARS-CoV-2 and transmission to humans could have started from bats [9]. However, the SARS-CoV-2 transitional animal host is still under investigation.

\section{Route of Infection of SARS-CoV-2 in Humans}

The envelope spike (S) protein has been observed to shape host tropism and transmission capacity. It also facilitates receptor binding and membrane fusion. Structural analysis revealed two domains (S1 domain and S2 domain) of S protein. The $\mathrm{S} 1$ domain facilitates binding to the receptor, whereas the $\mathrm{S} 2$ domain aids in fusion of the virus with the cell membrane. Like SARS-CoV, the SARS-CoV-2 also employs an angiotensin-converting enzyme 2 (ACE-2) receptors for entering into the host cells [10]. The ACE-2 has high expression in the lungs alveolar cells, the upper epithelial cells in the esophagus, and absorptive enterocytes cells of the ileum and colon. This indicates that along with the respiratory system, the digestive system could also act as a probable route of entry for SARS-CoV-2 [6]. The binding of SARS-CoV-2 to its receptor promotes the expression of ACE-2 that leads to alveolar cell damage that in turn activates a sequence of lethal reactions leading to death. As compared to European and American populations, the expression level of ACE-2 was observed significantly higher in the Asian populations and that too in males than females. The differential expression pattern of ACE-2 may form the basis of high rates of infection in Asian male population [11]. However, cases in Europe and America may have additional sensitivity or genetic predisposition.

Moreover, SARS-CoV-2 with its widespread potential and causing many infections has gained the potential to mutate, and several variants have hit the world with high rates. These variants based on the type of mutations may vary in the type of transmission (spread more or less) and severity. In the UK, a new variant of the virus known as B.1.1.7 emerged rapidly, with several other mutations. There was another variant of this virus that was found in South Africa and shared some of the mutations with B.1.1.7. This variant of SARS-CoV-2 is named B.1.351. Another variant known as P.1 was identified in Brazil. Some of these variants and their mutations spread more quickly and may be associated with an increased risk of death. The centers for disease control and prevention 
(CDC) with weblink (https://www.cdc.gov/corona virus/2019-ncov/science/science-briefs/scientific-brief-emergingvariants.html) in association with a wide array of partners worldwide, is providing data and information on these variants which can be used by public health professionals, researchers, and companies for public welfare.

\section{Epidemiology, Clinical Features and Pathological Conditions of COVID-19 Infection}

COVID-19 has caused a global pandemic (WHO Media Briefing held on 11th March 2020). The global reports have suggested that the individuals infected with SARS-CoV-2 had an average age of 59 years, among them males represent $56 \%$ of cases. The median incubation period for the virus was observed to be around 5 days. Also, the proportion of male-to-female mortality was observed to be high (3:1) with 75 years as the median age. Further, the median time between the onsets of symptoms to death is reported as 14 days that vary for patients with $\geq 70$ years of age (11.5 days) from the subjects aging $<70$ years (20 days) [12]. About half of the patients contracting COVID-19 infection were seen to have other diseased conditions, mainly hypertension, diabetes, or cardiovascular disease. With regard to children of age less than 15 years, comparatively, a smaller number of cases has been reported. Also, the clinical course was generally milder in children than adults infected with COVID-19 [6].

The COVID-19-infected patients showed fever with dry cough and fatigue as common clinical symptoms. Some patients were presented with upper respiratory symptoms, gastrointestinal symptoms such as vomiting, diarrhea and abdominal discomfort [5-7], and they were categorized into mild, severe, and critical medical conditions. The patients with mild symptoms were reported to have nonpneumonia or mild pneumonia. In severe conditions, observations suggest that oxygen saturation and partial pressure ratio of oxygen in arteries to inspire oxygen fraction decrease, whereas lung infiltrates may increase within a short span of 24-48 h [5]. The laboratory observation showed lymphopenia (low levels of lymphocytes) in the blood as a cardinal feature of COVID-19. Apart from this, the elevated levels of lactate dehydrogenase and creatinine kinase relate to abnormal myocardial zymograms. The patients also showed altered liver function with increased levels of alanine or aspartate aminotransferase [13]. Also, the levels of interleukins (IL10, IL9, IL8, IL7, IL1B, and IL1RA), granulocyte-macrophage colony-stimulating factor (GMCSF), granulocyte colony-stimulating factor (GCSF), fibroblast growth factor (FGF), interferon gamma-induced protein 10 (IP10), interferon-gamma (IFN$\gamma)$, macrophage inflammatory protein 1 alpha and beta (MIP1A, MIP1B), monocyte chemoattractant protein 1
(MCP1), platelet-derived growth factor (PDGF), vascular endothelial growth factor (VEGF), and tumor necrosis factor alpha (TNF $\alpha)$ concentrations were reported up in COVID-19 patients compared to healthy adults. They also noticed that plasma concentrations of $\mathrm{TNF} \alpha$ and interleukins (MIP1A, IP10, MCP1, GCSF, IL10, IL2, and IL7) were higher in patients admitted in the intensive care unit (ICU) indicating damage to the host lung due to the production of chemokines and cytokines upon the initiation of the immune response to COVID19 infection [14]. The reactome analysis (https://reactome.org), a high throughput in silico approach, was done in a subset of COVID-19 clinical data. The upregulated proteins predicted 25 biological pathways that may be affected in the COVID19 infected patients (Fig. 1). These pathways are related to the signaling of interleukin and cytokines, the inflammasome pathway, and chemokine receptors. The ATF4 activates genes in response to endoplasmic reticulum (ER) stress, regulation of gene expression by hypoxia inducing factor (HIF), VEGF-ligand receptor interaction, and dimerization, Dectin-1 signaling, cell recruitment (pro-inflammatory response). Further extensive studies are needed to identify specific molecular targets and trace critical molecular pathways to better understand the transmission and pathogenic nature of this pandemic infection.

The radiologic display observed using chest computed tomography (CT) scans of SARS-CoV-2 infected patients revealed patchy ground glass opacities (GGO) with condensation in the middle and outer zone of the lungs. Based on chest CT scans, four stages of abnormalities were observed in patients. The GGO appears in the lower lobes of either one or both the lungs in the early stage. In progressive stages, GGO appear bilateral, diffused and condensed in more than two lobes. However, diffuse GGO and compact consolidation developed more dominant in peak stage, whereas widespread GGO and condensation was progressively absorbed in the last or absorption stage $[5,14]$.

The lung biopsy reports of a few patients showed bilateral diffuse alveolar destruction with cellular fibromyxoid dislodge and interstitial mononuclear inflammatory penetration mainly by lymphocytes [5]. The SARSCoV2 viral cytopathic-like changes, i.e., multinucleated syncytial cells with unusually magnified pneumocytes identified in the intra-alveolar spaces, were similar to observation among patients infected with MERS-CoV and SARS-CoV. Further, liver tissue showed adequate microvascular steatosis, mild lobular, portal activity and heart tissue showed few interstitial mononuclear inflammatory infiltrates [14]. 


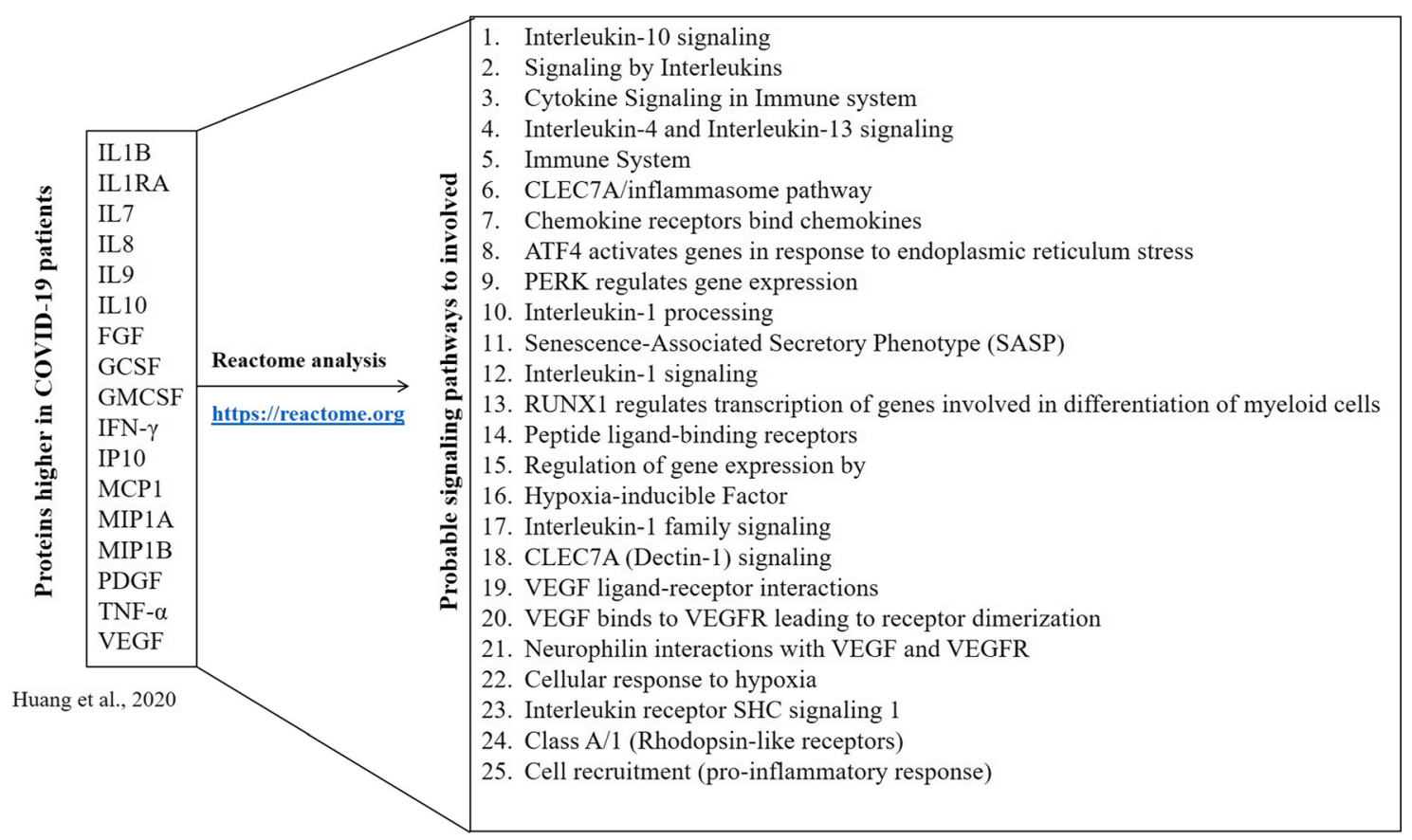

Fig. 1 In silico analysis of proteins through neural networks (Reactome analysis, https://reactome.org) indicates COVID19 infection may trigger innate and adaptive immune response, leading to activation of signaling pathways and signal transduction mechanisms

\section{Effect of COVID 19 Infection on Pregnancy}

The literature on the outcomes of COVID-19 infection during pregnancy is gradually building up. In two reports describing 18 pregnancies with COVID-19 where all were infected in the third trimester, the clinical findings were similar to those in non-pregnant adults. Fetal distress and preterm delivery were observed in a few cases. Out of all, two pregnancies were cesarean deliveries, and SARS-CoV2 was negative on all babies tested. Based on these limited reports, and the available data from other respiratory pathogens such as SARS and influenza, it is unknown whether pregnant women with COVID-19 experience more severe disease [15]. Further, another study on 141 COVID19 positive subjects also indicates a similar finding where no vertical transmission of COVID-19 infection nor its effect on maternal and fetal outcome was observed. [16]. However, further case studies and follow-ups of patients are of utmost importance to the large number of pregnant women affected with COVID-19 infection throughout the world to understand the probable effect of COVID-19 on the neonate and maternal health.

\section{Effect of COVID 19 on Nervous System}

Research and clinical data suggest that headache, weakness, dizziness, altered consciousness, hyposmia, encephalitis, neuropathy, seizure, demyelination, and stroke are some of the common symptoms in COVID-19 patients [17]. Further, agitation, confusion, enhanced tendon reflexes, clonus, olfactory and gustatory dysfunction are also observed in COVID-19 patients who require intensive care [18] CT scan and MRI reports in patients have also shown endothelial dysfunction and formation of clots in the brain and in multiple organs [19]. It has been proposed that COVID-19 infection may spread through the cribriform plate and olfactory bulb and dissemination via trans-synaptic transfer [17]. However, further studies are needed to identify how COVID-19 disease progression starts in the brain. The altered blood-brain barrier also recruits virus particles in the brain which can further cause neuronal toxicity [20]. Increased cytokine storms in COVID-19 patients also cause alteration in blood-brain barrier leading to penetration of peripheral immune cells in the brain results in seizures and encephalopathy-like conditions [21]. It will be interesting to investigate whether COVID19 spreads across the brain or got localized at a specific brain region. Likewise, COVID-19 related neurological pathologies should also be investigated mainly in the asymptomatic infection population. Like any other neurovirulent virus, COVID19 may also affect brainspecific immunity and cross the blood-brain barrier or reach directly to the brain through the olfactory bulb (Fig. 2). The microglia are innate immune cells of the brain, perform regular immunological surveillance of the brain and regulate brain immunity. Thus, microglia may be having a protective function coordinating the innate immune response like other microorganisms, however, the 


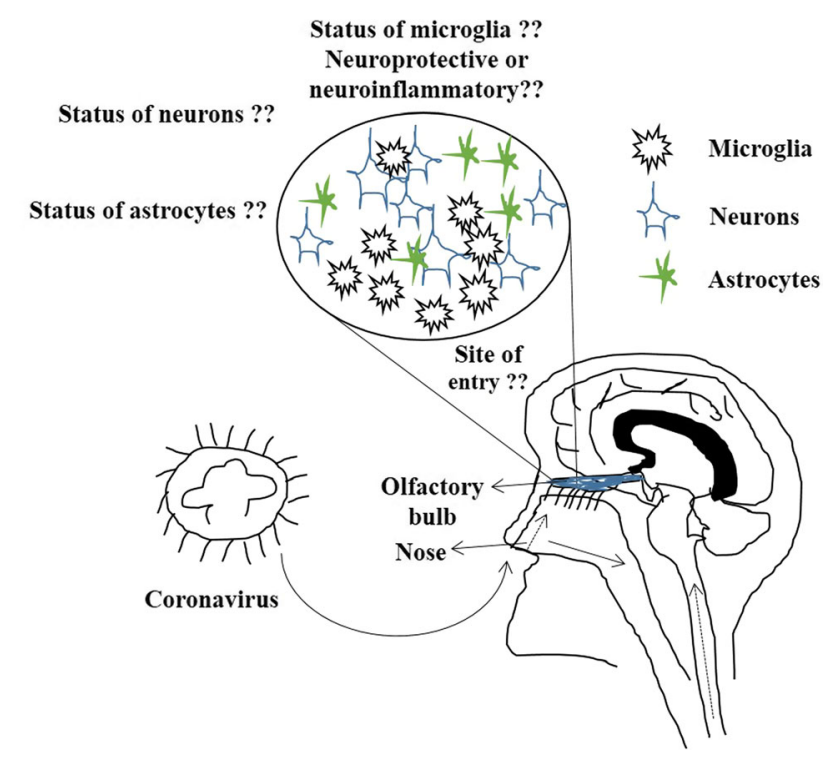

Fig. 2 Diagrammatic representation showing possible site of entry of COVID19 infection, either directly from the nose through the olfactory bulb into the brain or directly into the lungs and then migrate through the peripheral nervous system into the brain. Further, the underlying mechanism of whether microglia will be neuroprotective in nature if COVID19 virus enters through the olfactory bulb or it will initiate neuroinflammation cascade still remains elusive. The status of neurons and astrocytes at the site of virus entry remains unknown till date

above-mentioned underlying mechanisms still remain unclear.

\section{Effect of COVID 19 on Individuals Having Diabetes and Cardiovascular Disease}

Diabetic individuals are at greater risk of infections and are highly prone to influenza and pneumonia-like MERS CoV, SARS CoV, and Pandemic Influenza A 2009 (H1N1). It is suggested that the presence of medical conditions like diabetes and cardiovascular disease with SARS-CoV2 infection can increase the mortality risk in the population [22]. It has been hypothesized that pneumonia can potentially cause a low level of oxygen in the blood due to gas exchange obstruction, which will adversely affect the cell metabolism, increase anaerobic fermentation, intracellular acidosis, and oxygen free radicals which will further damage the phospholipid bilayer of the cell membrane [23]. At the same time, calcium ions influx due to hypoxia can damage cardiac muscle cells. In such stress conditions and due to medication, the release of neurotransmitters mainly catecholamines, in an excess amount can cause myocardial damage. It is also suggested that cardiac diseases, hypertension, or diabetic patients are prone to severe COVID-19 infection when treated with ACE2-increasing drugs [24]. Thus, ACE inhibitors or ARBs (angiotensin II
type-I receptor blockers) have been proposed to modulate ACE2 medications in such patients. Further, based on patients with COVID-19 studies, Chen et al., 2020 proposed that COVID-19 can significantly affect the heart function and lead to myocardial injury [25].

\section{Diagnosis of COVID-19}

The general approaches to detect COVID-19 are molecular and serological tests. Currently, the standard diagnostic test for SARS-CoV-2 infection using samples taken from the respiratory tract by PCR techniques such as RT-PCR, RTinsulated isothermal PCR, RT-LAMP, and single-step rRTPCR assay based on specific TaqMan probes. The whole genome sequencing may also be carried out on positive samples to aid understanding of transmission and mutations. In comparison, molecular tests (RT-PCR) have shown higher sensitivity than serological (ELISA) tests. For improving the sensitivity of the test, an additional sensitive molecular marker, i.e., $N$ gene, has been incorporated into nested PCR [26]. Further, CT scan has also been considered the most reliable method to identify and validate COVID19 infection in patients. However, efforts are still going on in the direction of using NGS (Next Generation Sequencing) and CRISPR (Clustered Regularly Inter Spaced Palindromic Repeats) Technology as Point-ofCare diagnostic tools [27] to detect COVID-19 infection even at the early stage in a minimum possible testing time with high sensitivity.

\section{Drug Repurposing Strategies for COVID-19}

James Black, Nobel laureate, excellently quoted that "The most fruitful basis of the discovery of a new drug is to start with an old drug." [28]. Thus, the concept of Drug repurposing, which is also coined as Drug repositioning or Drug reprofiling developed and helped bring new therapies to the world (Table 1). Drug repurposing is basically defined as the reapplication of the approved drugs or failed drugs to target new indication(s). Three R's (Repositioning, Reprofiling, and Repurposing) strategy has served as an important part of the drug development process of pharmaceutical business for the last few decades. It helps to adjust or develop multiple applications of an active molecule. The advantage of using the existing drugs is that they have known pharmacokinetics, pharmacodynamics, clinical history, and safety profile data for human use. Thus, repurposing may reduce early testing and clinical trials and dramatic dropping development times and cost.

The repurposing strategy has highlighted many other potential candidates also such as leronlimab, a CCR5 antagonist with the potential for multiple therapeutic indications, and galidesivir, a nucleoside RNA polymerase 
Table 1 Some of the classic examples of repurposed drugs

\begin{tabular}{lll}
\hline Drug & Original indication & Repurposed indication \\
\hline $\begin{array}{l}\text { Thalidomide } \\
\text { Ropinirole }\end{array}$ & Sedative & Leprosy and Multiple myeloma \\
Pregabalin and Gabapentin & Restless legs syndrome, sexual dysfunction \\
induced by selective serotonin reuptake inhibitor (SSRI) \\
Minoxidil & Anti-epileptics & Neuropathic pain and anxiety disorders \\
Methotrexate & Anti-hypertensive agent & Topical treatment for hair re-growth \\
Gemcitabine & Chemotherapy drug & Autoimmune disorders including arthritis \\
Raloxifene & Anti-viral & Anticancer \\
Buproprion & Breast cancer & Osteoporosis \\
Dapoxetine & Depression & Smoking cessation \\
Dapsone (DDS) & Analgesia & Premature ejaculation \\
Fluxetine & Antileprosy drug & Antimalarial \\
Doxepin & Depression & Premenstrual dysphoria disorder (PMDD) \\
Bimatoprost & Antidepressant & Antipruritic \\
\hline Paperash & Glaucoma & Eyelash growth
\end{tabular}

Papapetropoulos and Szabo [31], Insa [32]

inhibitor, favipiravir, darunavir, immunoglobulins, arbidol hydrochloride combined with interferon atomization and others [7] (Table 2). In another study, open label nonrandomized clinical trials showed that hydroxychloroquine treatment significantly reduce the viral load in COVID-19 patients, where providing azithromycin along with hydroxychloroquine enhanced its anti-viral effect [29]. However, the efficacy and safety of hydroxychloroquine is still under investigation. Another protease inhibitor, lopinavir/ritonavir, conventionally used for HIV-1 treatment,

Table 2 List of drugs considered potential to repurpose for COVID-19 infection treatment

\begin{tabular}{|c|c|c|c|}
\hline Drug & Action mode & Mechanism & Target disease \\
\hline $\begin{array}{l}\text { Chloroquine } \\
\text { phosphate }\end{array}$ & 9-aminoquinolin & Immunomodulating, autophagy inhibitors, raising endosomal $\mathrm{pH}$ & $\begin{array}{l}\text { Malaria, autoimmune } \\
\text { disease }\end{array}$ \\
\hline Remdesivir & Nucleotide analog & Post entry interference with virus & SARS, MERS \\
\hline $\begin{array}{l}\text { Lopinavir/ } \\
\text { Ritonavir }\end{array}$ & Protease inhibitor & Inhibits HIV-1 protease for protein cleavage & HIV/AIDS, SARS, MERS \\
\hline Ribavirin & $\begin{array}{l}\text { Synthetic guanosine } \\
\text { nucleoside }\end{array}$ & Interfering with the synthesis of viral mRNA & HCV, SARS, MERS \\
\hline Favipiravir & $\begin{array}{l}\text { Viral RNA } \\
\text { polymerase } \\
\text { inhibitor }\end{array}$ & $\begin{array}{l}\text { Acts on genetic copying of virus, prevents its reproduction without } \\
\text { affecting nucleic acid synthesis of host cell }\end{array}$ & Ebola, H1N1 Influenza \\
\hline Nitazoxanide & Antiprotozoal agent & $\begin{array}{l}\text { Modulating growth and proliferation of microbes like protozoa, } \\
\text { helminths, virus and bacteria }\end{array}$ & Human/anima coronavirus \\
\hline Ganciclovir & Nucleoside analog & Inhibitor of herpesvirus family including cytomegalovirus & $\begin{array}{l}\text { AIDS-associated } \\
\text { cytomegalovirus } \\
\text { infections }\end{array}$ \\
\hline Nafamostat & $\begin{array}{l}\text { Synthetic serine } \\
\text { protease inhibitor }\end{array}$ & Reduces release of cathepsin B, anticoagulant activity & Ebola, MERS, Influenza \\
\hline Oseltamivir & $\begin{array}{l}\text { Neuraminidase } \\
\text { inhibitor }\end{array}$ & $\begin{array}{l}\text { Prevents viral replication and infectivity by inhibiting viral } \\
\text { neuraminidase }\end{array}$ & Influenza viruses $A$ \\
\hline Darunavir & $\begin{array}{l}\text { Antiretroviral } \\
\text { protease inhibitor }\end{array}$ & $\begin{array}{l}\text { Inhibiting of HIV-1 protease and blocks the cleavage of HIC gag-pol } \\
\text { polyprotein }\end{array}$ & HIV/AIDS \\
\hline IFN-beta & $\begin{array}{l}\text { Anti-inflammatory } \\
\text { agent }\end{array}$ & Reduces antigen presentation and T-cell proliferation & Hepatitis, Ebola \\
\hline
\end{tabular}

Guo et al. [7] 
have shown potential to act on SARS-CoV-2 and is advised to the high-risk group of COVID-19 pneumonia in the Korean population. The controlled clinical trials suggest no effect of lopinavir/ritonavir on COVID-19 [30]. The BCG vaccination has also been proposed as an alternative treatment strategy in reducing COVID19 infection mortality rate. Recently, the compassionate use of anti-viral drug Remdesivir (RDV) has been suggested to be effective in severe COVID-19 infected individuals. However, COVID19 specific drug is still under investigation.

Apart from hunting for the drug against COVID-19, scientists across the world have tried and come up with another possibility to protect individuals from COVID-19 infection, i.e., through immunization. COVID-19 specific vaccine has been developed in different parts of the world and a vaccination drive has been started. However, the efficacy of vaccines developed needs to be improved for which further research is underway. Till now, $1,011,457,859$ vaccine doses have been administered to individuals globally, according to WHO data indicating that we have to go a long way to immunize and protect our population with COVID-19. Therefore, the identification and development of COVID-19 specific drugs are of utmost importance for treatment purposes.

\section{COVID-19 Infection in India}

Humans serve as hosts to the number of respiratory viruses. Respiratory transmission from human to human is one of the preliminary causes of viral infections including measles and COVID-19. Due to the large population size (approximately 1.38 billion) Indians live closer so that it is easier for pathogens to jump from one host to another via air or surface transmission. Their reservoir is also facilitated due to the 4 climatological seasons of about three months each.

The first case of COVID-19 in India was detected on 30th January 2020. Soon after, quarantine centers were established and admitted for monitoring for citizens from traveling to China and other parts of the world (Source: PIB Daily Bulletin on COVID-19 matters, Government of India, https://pib.gov.in/newsite/bulletinn.aspx). Due to proactive measures of complete lockdown and monitoring, the spread of infection came under control as compared to other countries [4] (Fig. 4). Meanwhile, based on the whole genome sequence of the first Indian COVID19 case, genespecific in vitro transcribed RNA for all the gene targets, i.e., $N, E$ and $R d R p$, as an in-house positive control for laboratory diagnosis of SARS-CoV-2 by the National Institute of Virology, Indian Council of Medical Research, Pune, India. The genome sequences of Indian SARS-CoV2 showed approximately $99.98 \%$ similarity with that of (Accession number: NC 045,512) but belong to different clusters in phylogenetic analysis. Due to the non- availability of any specific treatment for COVID-19, lopinavir/ritonavir combination therapy and remdesivir have been approved for COVID-19 under restricted public health emergency by Central Drugs Standard Control and Indian Regulatory Authority. Recently, the second wave of COVID-19 infection in India has caused tremendous damage to the life of people, therefore setting up a new pandemic rate worldwide. As per WHO data, there have been 19,164,969 confirmed cases with 211,853 deaths from 3rd January 2020 to 1st May 2021. The spread of new variants with the potential of causing severe damage has been one of the reasons for this widespread use. Some of the common symptoms being observed in infected people include fever, headache, cough and breathlessness. Moreover, the young population appears to be most affected by this second wave. Additionally, there have been double and triple mutant strains which are still evolving further to evade the human immune response. Thus, as a prevention measure, a large vaccination drive has started and till date $147,727,054$ vaccine doses have been administered among individuals with above age group of 45 and above. Vaccines including Covaxin, AstraZeneca and Sputnik, which are some of the vaccines being approved by WHO against COVID-19, which may provide a high degree of protection against getting seriously ill and dying from the disease although no vaccine is $100 \%$ protective. Moreover, it will take longer time to vaccinate the whole Indian population.

\section{Conclusion}

COVID-19 infection is causing major public health problems across the globe. Apart from severe respiratory illness, COVID-19 infection seems to affect multiple organs. Some drugs have shown promising results, however, novel standard treatment regimes and potent interventions are the need of the hour. Rapid immunization at the large scale at the global level is urgently required to boost our immune response against COVID-19 infection. These comprehensive studies, genomic data, epidemiology data, and clinical details positively support a novel and comprehensive diagnosis and treatment options in upcoming days to beat COVID-19.

Acknowledgments SKM, and AB, acknowledges Ramjas College, University of Delhi, Delhi for its continuous support and motivation. RM acknowledges the Department of Zoology, Banaras Hindu University, Varanasi for support. SKM also acknowledge Dr. Amrita Bakshi, Department of Zoology, University of Delhi, Delhi for providing critical comments and suggestions while writing the manuscript. PS acknowledges guidance and support from the National Institute of Malaria Research, Indian Council of Medical Research, Delhi. 
Author's Contributions SKM conceptualized the manuscript. SKM, $\mathrm{AB}$ and PS wrote the manuscript. SKM, AB and RM reviewed and edited the manuscript. All authors approved the manuscript before submission.

Funding This research did not receive any specific grants from funding agencies in the public, commercial, or not-for-profit sectors.

\section{Declarations}

Conflict of Interest SKM, AB, PS, and RM declare no conflict of interest.

\section{References}

1. Wang C, Horby PW, Hayden FG, Gao GF (2020) A novel coronavirus outbreak of global health concern. Lancet 395(10223):470-473

2. World Health Organization. Coronavirus disease 2019 (COVID19) Situation Report-161. https://www.who.int/emergencies/ diseases/novel-coronavirus-2019/ situation-reports/

3. Tang X, Wu C, Li X, Song Y, Yao X, Wu X, Duan Y, Zhang H, Wang Y, Qian Z, Cui J, Lu J (2020) On the origin and continuing evolution of SARS-CoV-2. Natl Scie Re. https://doi.org/10.1093/ nsr/nwaa036

4. Wang Y, Li X, Liu W, Gan M, Zhang L, Wang J, Zhang Z, Zhu A, Li F, Sun J, Zhang G, Zhuang Z, Luo J, Chen D, Qiu S, Zhang L, Xu D, Mok C, Zhang F, Zhao J, Zhao J (2020) Discovery of a subgenotype of human coronavirus NL63 associated with severe lower respiratory tract infection in China, 2018. Emerg Microbes infect 9(1):246-255. https://doi.org/10.1080/22221751.2020. 1717999

5. He F, Deng Y, Li W (2020) Coronavirus disease 2019: What we know? J Med Virol. https://doi.org/10.1002/jmv.25766

6. Lu R, Zhao X, Li J et al (2020) Genomic characterisation and epidemiology of 2019 novel coronavirus: implications for virus origins and receptor binding. Lancet 395(10224):565-574. https://doi.org/10.1016/S0140-6736(20)30251-8

7. Guo YR, Cao QD, Hong ZS et al (2020) The origin, transmission and clinical therapies on coronavirus disease 2019 (COVID-19) outbreak - an update on the status. Mil Med Res 1:11. https://doi.org/10.1186/s40779-020-00240-0

8. Wu F, Zhao S, Yu B et al (2020) A new coronavirus associated with human respiratory disease in China. Nature. https://doi.org/ 10.1038/s41586-020-2008-3

9. Sun P, Lu X, Xu C, Sun W, Pan B (2020) Understanding of COVID-19 based on current evidence. J Med Virol. https:// doi.org/10.1002/jmv.25722.10.1002/jmv.25722

10. Belouzard S, Millet JK, Licitra BN, Whittaker GR (2012) Mechanisms of coronavirus cell entry mediated by the viral spike protein. Viruses 4(6):1011-1033. https://doi.org/10.3390/ v4061011

11. Zhang Q, Cong M, Wang N et al (2018) Association of angiotensin-converting enzyme 2 gene polymorphism and enzymatic activity with essential hypertension in different gender: a casecontrol study. Medicine (Baltimore) 97(42):e12917. https://doi.org/10.1097/MD.0000000000012917

12. Wang W, Tang J, Wei F (2020) Updated understanding of the outbreak of 2019 novel coronavirus (2019-nCoV) in Wuhan. China J Med Virolm 92(4):441-447. https://doi.org/10.1002/ jmv.25689

13. Huang C, Wang Y, Li X et al (2020) Clinical features of patients infected with 2019 novel coronavirus in Wuhan. China Lancet
395(10223):497-506. https://doi.org/10.1016/S0140-6736(20)30 183-5

14. Hui DSC, Zumla A (2019) Severe acute respiratory syndrome: historical, epidemiologic, and clinical features. Infect Dis Clin North Am 33(4):869-889. https://doi.org/10.1016/ j.idc.2019.07.001

15. Rasmussen SA, Smulian JC, Lednicky JA, Wen TS, Jamieson DJ (2020) Coronavirus disease 2019 (COVID-19) and pregnancy: what obstetricians need to know. Am J Obstet Gynecol. https://doi.org/10.1016/j.ajog.2020.02.017

16. Nayak AH, Kapote DS, Fonseca M, Chavan N, Mayekar R, Sarmalkar M, Bawa A (2020) Impact of the coronavirus infection in pregnancy: a preliminary study of 141 patients. J Obstet Gynaecol India 70(4):256-261. https://doi.org/10.1007/ s13224-020-01335-3

17. Montalvan V, Lee J, Bueso T, De Toledo J, Rivas K (2020) Neurological manifestations of COVID-19 and other coronavirus infections: a systematic review. Clin Neurol Neurosurg 194:105921. https://doi.org/10.1016/j.clineuro.2020.105921

18. Orsucci D, Ienco EC, Nocita G, Napolitano A, Vista M (2020) Neurological features of COVID-19 and their treatment: a review. Drugs Context. https://doi.org/10.7573/dic.2020-5-1

19. Goldberg MF, Goldberg MF (2020) Neuroradiologic manifestations of COVID-19: what the emergency radiologist needs to know. Emerg Radiol 27(6):737-745. https://doi.org/10.1007/ s10140-020-01840-y

20. Anwar MM, Badawi AM, Eltablawy NA (2020) Can the coronavirus infection penetrates the brain resulting in sudden anosmia followed by severe neurological disorders? eNeurological Sci 21:100290. https://doi.org/10.1016/j.ensci.2020.100290

21. Thepmankorn P, Bach J, Lasfar A, Zhao X, Souayah S, Chong ZZ, Souayah N (2021) Cytokine storm induced by SARS-CoV-2 infection: the spectrum of its neurological manifestations. Cytokine 138:155404. https://doi.org/10.1016/j.cyto.2020.155404

22. Gupta R, Ghosh A, Singh AK, Misra A (2020) Clinical considerations for patients with diabetes in times of COVID-19 epidemic. Diabetes Metab Syndr 14(3):211-212. https://doi.org/10. 1016/j.dsx.2020.03.002

23. Li B, Yang J, Zhao F et al (2020) Prevalence and impact of cardiovascular metabolic diseases on COVID-19 in China. Clin Res Cardiol. https://doi.org/10.1007/s00392-020-01626-9

24. Fang L, Karakiulakis G, Roth M (2020) Are patients with hypertension and diabetes mellitus at increased risk for COVID19 infection? Lancet Respir Med S2213-2600(20):30116-30118. https://doi.org/10.1016/S2213-2600(20)30116-8

25. Chen C, Chen C, Yan JT, Zhou N, Zhao JP, Wang DW (2020) Analysis of myocardial injury in patients with COVID-19 and association between concomitant cardiovascular diseases and Severity of COVID-19. Zhonghua Xin Xue Guan Bing Za Zhi 48:E008. https://doi.org/10.3760/cma.j.cn112148-20200225-00 123

26. Pang J, Wang MX, Ang IY, Tan SH, Lewis RF, Chen JI et al (2020) Potential rapid diagnostics, vaccine and therapeutics for 2019 novel coronavirus (2019-nCoV): a systematic review. J Clin Med 9:E623. https://doi.org/10.3390/jcm9030623

27. Azhar M, Phutela R, Kumar M, Ansari AH, Rauthan R, Gulati S, Sharma N, Sinha D, Sharma S, Singh S, Acharya S, Sarkar S, Paul D, Kathpalia P, Aich M, Sehgal P, Ranjan G, Bhoyar RC, Indian CoV2 Genomics \& Genetic Epidemiology (IndiCovGEN) Consortium, Singhal, K., ... Maiti S (2021) Rapid and accurate nucleobase detection using FnCas9 and its application in COVID19 diagnosis. Biosens Bioelectron 183:113207. https://doi.org/ 10.1016/j.bios.2021.113207

28. Bradley D (2005) Why big pharma needs to learn the three 'R's. Nat Rev Drug Discov 4(6):446. https://doi.org/10.1038/nrd1766 
29. Gautret P, Lagier JC, Parola P et al (2020) Hydroxychloroquine and azithromycin as a treatment of COVID-19: results of an open-label non-randomized clinical trial. Int $\mathrm{J}$ Antimicrob Agents. https://doi.org/10.1016/j.ijantimicag.2020.105949

30. Cao B, Wang Y, Wen D et al (2020) A trial of lopinavir-ritonavir in adults hospitalized with severe Covid-19. N Engl J Med. https://doi.org/10.1056/NEJMoa2001282.10.1056/NEJMoa 2001282

31. Papapetropoulos A, Szabo C (2018) Inventing new therapies without reinventing the wheel: the power of drug repurposing. $\mathrm{Br}$ J Pharmacol 175(2):165-167. https://doi.org/10.1111/bph.14081
32. Insa R (2013) Drug repositioning: bringing new life to shelved assets and existing drugs. Edited by 431 Michael J. Barratt and Donald E. Frail Chem Med Chem 8:336-337. https://doi.org/10.1002/cmdc.201200552

Publisher's Note Springer Nature remains neutral with regard to jurisdictional claims in published maps and institutional affiliations. 